\title{
Erratum to: Petrographical and petrophysical characteristics of asynchronous beachrocks along Al-Shoaiba Coast, Red Sea, Saudi Arabia
}

\author{
Ibrahim M. Ghandour • Hamad A. Al-Washmi • \\ Rashad A. Bantan • Mohamed M. Gadallah
}

Published online: 13 February 2013

(C) Saudi Society for Geosciences 2013

Erratum to: Arab J Geosci

DOI 10.1007/s12517-012-0826-9

Ibrahim M. Ghandour and Mohamed M. Gadallah's Geology Department affiliations should not be captured as Present Address.

The correct authors' affiliations are given below.

The online version of the original article can be found at http://dx.doi.org/ 10.1007/s12517-012-0826-9.

I. M. Ghandour $(\bowtie) \cdot$ H. A. Al-Washmi • R. A. Bantan

Marine Geology Department, Faculty of Marine Science,

King Abdulaziz University, P.O. Box 80207, Jeddah 21589,

Saudi Arabia

e-mail: ighandour@kau.edu.sa

M. M. Gadallah

Deanship of Scientific Research, King Abdulaziz University, P.O.

Box 80230, Jeddah 21589, Saudi Arabia

I. M. Ghandour

Geology Department, Faculty of Science, Tanta University, Tanta

31527, Egypt

M. M. Gadallah

Geology Department, Faculty of Science, Damanhur University,

Damanhur, Egypt 